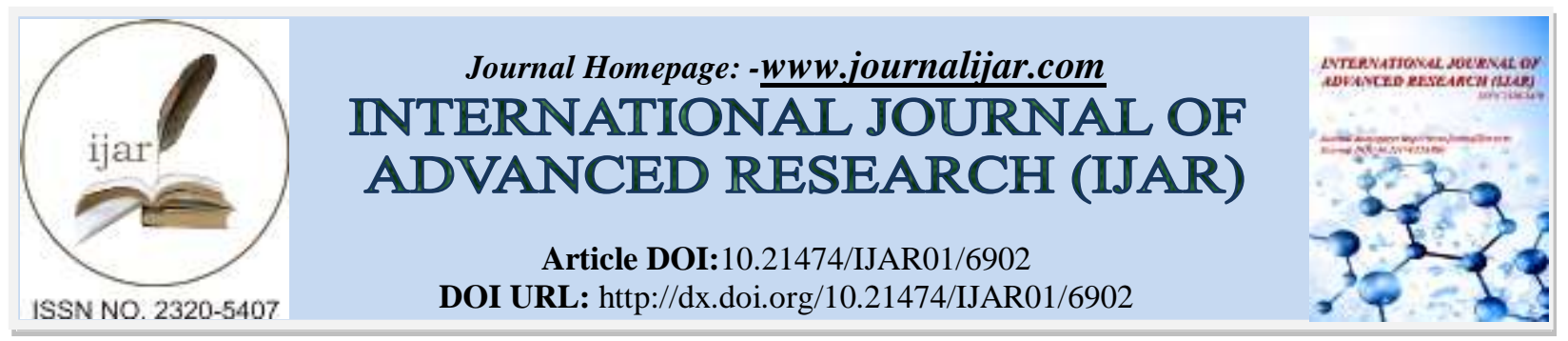

RESEARCH ARTICLE

\title{
EFFECT OF BONE MARROW DERIVED MESENCHYMAL STEM CELLS VS ALENDRONATE SODIUM IN TREATMENT OF INDUCED ESTROGEN DEFICIENCY OSTEOPOROSIS IN ALVEOLAR BONE OF ALBINO RATS.
}

Marwa M. Abd El Hameed and Iman A. Fathy.

Lecturer of oral biology, Faculty of dentistry, Ain Shams university.

\section{Manuscript Info}

Manuscript History

Received: 10 February 2018

Final Accepted: 12 March 2018

Published: April 2018

Keywords:-

Postmenopausal Osteoporosis-Bmmscs-

Alendronate Sodium-Ovariectomy.

\begin{abstract}
Background: Despite extensive efforts for the understanding and curative options for osteoporosis, it remains a critical public health threat. Alendronate sodium, an amino bisphosphonate, is a potent antiresorptive drug used in the treatment of osteoporosis in postmenopausal women. On the other hand, BMMSCS are considered one of the recent therapeutic modalities that promote bone regeneration by increasing the number and activity of osteoblasts. Hence, based on the role of alveolar bone in dentistry, it is important to study the effect of estrogen deficiency and its therapies on tooth-supporting alveolar bone.

Aim: The aim of this study was to investigate the influence of an estrogen deficient state in rats, and its treatments namely BMMSCs and Alendronate sodium, on the structure of tooth-supporting alveolar bone. Methodology: Forty-eight female albino rats were divided equally into 4 groups: Gp 1 received only distilled water during the whole experimental duration. Gps 2, 3 and $\mathbf{4}$ underwent bilateral ovariectomy where Gp 2 received no treatment, group 3 was treated by Alendronate sodium and finally group 4 received BMMSCs injection. After 4 weeks samples from all groups were collected and evaluated using hematoxylin and eosin as well as Masson trichrome. Number of osteocytes and thickness of bone trabeculae were statistically analyzed.

Results: The histological examination revealed obvious enhancement of the alveolar bone condition by both modalities of treatment however statistically insignificant outcomes were observed regarding mesenchymal stem cell treated group.

Conclusion: BMMSCs injection does not significantly overcome the effect of the most widely used Alendronate Sodium in treatment of alveolar bone osteoporosis in ovariectomized rats.
\end{abstract}

Copy Right, IJAR, 2018,. All rights reserved.

\section{Introduction:-}

Bisphosphonates are among the indicated medications for the treatment of osteopenic and osteoporotic conditions. ${ }^{[1]}$ The amino-bisphosphonate alendronate sodium (ALN) is one of the most commonly used medications for osteoporotic cases due to its high potential for bone resorption inhibition. ${ }^{[2,3]}$ ALN has a strong affinity for 
circulating calcium and other minerals at bone surfaces ${ }^{[4]}$ and inhibits enzyme activity in osteoclasts, thereby diminishing the dissolution of bone tissue and the degradation of collagen. ${ }^{[4]}$ ALN also induces some biochemical events that are capable of initiating apoptosis in osteoclasts. ${ }^{[5,6,7]}$

Thus, bisphosphonates contribute to the control of bone turnover and preventing osteopenia/osteoporosis. Case reports involving patients submitted to prolonged bisphosphonate treatment describe lower rates of tooth movement, which hinders orthodontic treatment. ${ }^{[8,9]}$ How-ever, further evidence is needed to determine the extent to which altered bone metabolism in patients under systemic treatment for osteopenia and osteoporosis affects tooth movement. ${ }^{[10,11,12]}$ The experimental ovariectomy is an important study model that could evaluate the consequences of mass bone loss in several sites in animal models. ${ }^{[10]}$ since it is increasingly frequent occurrence of individuals with osteopenia and osteoporosis under treatment with alendronate sodium in dental offices.

Osteoporosis and low bone mineral density (BMD) affect more than 55 million people in the united states ${ }^{[13]}$ and Canada. ${ }^{[14]}$ These conditions are responsible for over two million fragility fractures every year. ${ }^{[15]}$ Osteoporotic hip fractures are of concern, as over 300,000 cases occur yearly in the U.S., leading to associated deaths, and disabling half of those who survive. ${ }^{[16]}$ Associated health care costs and morbidity are expected to rise due to an aging demographic. ${ }^{[17]}$ Osteoporosis is caused by an imbalance between the tightly regulated process of bone formation by osteoblasts and resorption by osteoclasts. Primary osteoporosis is defined as bone loss attributed to aging or a decline in sex hormones associated with aging, whereas secondary osteoporosis is bone loss caused by an unrelated pathological condition. ${ }^{[18,19,20]}$ Primary osteoporosis is classified as two categories, postmenopausal osteoporosis (type I) and age-related osteoporosis (type II, or senile). The mechanism underlying postmenopausal osteoporosis is associated with excessive bone resorption, caused by oestrogen deficiency, and often managed with antiresorptive bisphosphonate therapy. On the contrary, age-related osteoporosis involves the gradual loss of bone caused by insufficient bone formation.

The lack of an overall understanding mechanism of what drives age-related osteoporosis has hindered the development of anabolic therapy appropriately targeting the etiology of the disease. It is hypothesized that decrease in the number and function of bone and bone marrow (BM)- derived mesenchymal stromal cells (MSCs) - a heterogeneous population comprising skeletal stem cells (SSCs), osteoblastic cells, and fibroblasts-lies at the root of age-related bone loss. ${ }^{[21,22,23]}$

Specifically, age-related changes in the proliferative and differentiation capacity of BM-MSCs are suspected, ${ }^{[24]}$ and recent evidence suggests that the loss of SSCs, which are a rare subset of MSCs, could be the most related event in the progression of senile bone loss. ${ }^{[25,26]}$ Thus, treatment strategies aimed at replenishing the MSCs compartmentand by extension SSCs - or augmenting endogenous populations of these cells, could result in bone growth and combat age-related osteoporosis. Bone is a dynamic tissue, with remodelling-mediated maintenance regenerating the entire skeleton every 10 years. ${ }^{[27]}$

Homeostasis is achieved when bone formation by osteoblasts, the terminally differentiated phenotype within the MSC pool, equals resorption by osteoclasts derived from the hematopoietic compartment. Alarm of this balance caused by reduced formation, or excessive resorption, can manifest itself in osteopenia or, more seriously, osteoporosis. The etiology behind postmenopausal osteoporosis is well characterized and is related to the loss of oestrogen after menopause due to ovarian atrophy results in an anti-osteoblast, pro-osteoclast environment.

Bisphosphonates are usually the first line treatment for postmenopausal osteoporosis; however, oestrogen replacement is also an option. Following menopause, a slower phase of bone loss persists, and continues for the remainder of the woman's life, and equally affects cortical and trabecular bone ${ }^{[28]}$. In comparison, the decline of BMD in men occurs from midlife onward, with progressive trabecular and cortical bone loss nearly equivalent to the second phase of bone loss in women. However, the lack of oestrogen-mediated postmenopausal bone loss results in less overall BMD decline. ${ }^{[28]}$ Nevertheless, the molecular mechanisms underlying type II osteoporosis are not well understood, and patients usually receive bisphosphonates, a treatment designed for postmenopausal osteoporosis. If osteoporosis persists, intermittent parathyroid hormone (PTH) treatment may be prescribed due to early phase anabolic effects but the costs ${ }^{[29]}$ and short duration of effects limit its use ${ }^{[30]}$.

The objective of the present work was to assess the effect of stem cell injection versus Alendronate sodium in improving the osteoporotic changes in ovariectomized female albino rats. 


\section{Material and Methods:-}

Animals:-

The experimental animals were 48 adult female albino rats (90d old) that weighed an average of $211 \mathrm{~g}(208-214 \mathrm{~g})$ at the beginning of the study. During the period of the experiment, the animals were kept in plastic cages with access to food and drinking water ad libitum, with the exception of the ovariectomized rats (pair feeding). ${ }^{[31]}$ This protocol was approved by the faculty of medicine, Ain Shams University Animal Care and Use Committee.

\section{Ovariectomy:-}

At the beginning of the study, the animals were anesthetized by intramuscular administration of ketamine $(0.5 \mathrm{ml} / \mathrm{kg})$. Bilateral ovariectomies (OVXs) were performed in all rats from a dorsal approach, Postoperatively, the animals received antibiotic given as a single intramuscular injection $\left(1 \mathrm{ml} / \mathrm{kg}\right.$ ) (Augmentin ${ }^{\circledR}$; GlaxoSmithKline, NZ limited, Auckland, New Zealand). ${ }^{[32]}$

\section{Drug administration:-}

Alendronate sodium (5mg) supplied as tablets (FOSAMAX®, Merck \& Co. Inc., Whitehouse Station, NJ, USA) was prepared in powder form and dissolved in distilled water then administered into the oral cavity once a day via a tube for 4 weeks in a dose of $2 \mathrm{ml} / \mathrm{kg}$. ${ }^{[33]}$

\section{Experimental design:-}

At the beginning of the study, the animals were randomly assigned to one of the following four groups:

1. Group $1(n=12)$ : (negative control) given distilled water of $2 \mathrm{ml} / \mathrm{kg}$ daily by oral gavage.

2. Group 2 ( $\mathrm{n}=12)$ : (positive control) rats that were subjected to bilateral ovariectomy.

3. Group $3(n=12)$ : (OVX + Alendronate) bilateral ovariectomy plus Alendronate sodium administered to the rats daily by oral gauge for 4 weeks in the volume of $2 \mathrm{ml} / \mathrm{kg}$.

4. Administration of drug started 2 days after bilateral ovariectomy and continued for 28 days. ${ }^{\text {[33] }}$

5. group $4(n=12)$ : (OVX +BMMSCs) plus $1 \mathrm{ml}$ injection of bone marrow derived stem cells as a single dose IV injection in tail vein $(1 \mathrm{ml}=2$ million cells $){ }^{[34]}$

\section{Histologic examination procedure:-}

At the end of the experimental period, the animals were killed. The lower jaws were dissected and the specimens were fixed in $4 \%$ neutral formalin for $48 \mathrm{~h}$ and subsequently demineralized in a solution containing equal parts of $50 \%$ formic acid and $20 \%$ sodium citrate for 30 days. Once demineralization was achieved and checked by sharp probe, specimens were processed and paraffin serial buccolingual sections $(6 \mu \mathrm{m})$ were obtained. ${ }^{[35]}$ Some of these sections were stained by hematoxylin and eosin while others were stained by masson trichrome, histomorphmetric data of trabecular thickness and osteocyte cell count were collected and tabulated for statistical analysis.

\section{Results:-}

\section{Hx \& E results:-}

Group 1(control group):-

The socket wall appeared regular without noticed scalloping, zones of defined alveolar bone proper were clearly distinguished. Zucker kandle and Hershfield canals appeared with almost regular diameter width. Bone trabeculae are wide (average thickness \pm 60 micrometer). Most osteoblasts appeared cuboidal in shape while osteocytes showed clear lamina limitans in some zones or else empty lacunae were observed (average number of osteocytes was +24$)$. The lymphocytic aggregation was observed in the bone marrow. Periosteum on the other hand showed thick fibrous layer together with a regular layer of active osteoblasts. In compact bone regular round haversian canals were observed ( Fig. 1 A, B, $C, D, E \& F$ ).

\section{Masson trichrome results:-}

Blue areas were dominating, in both posterior and anterior regions. 


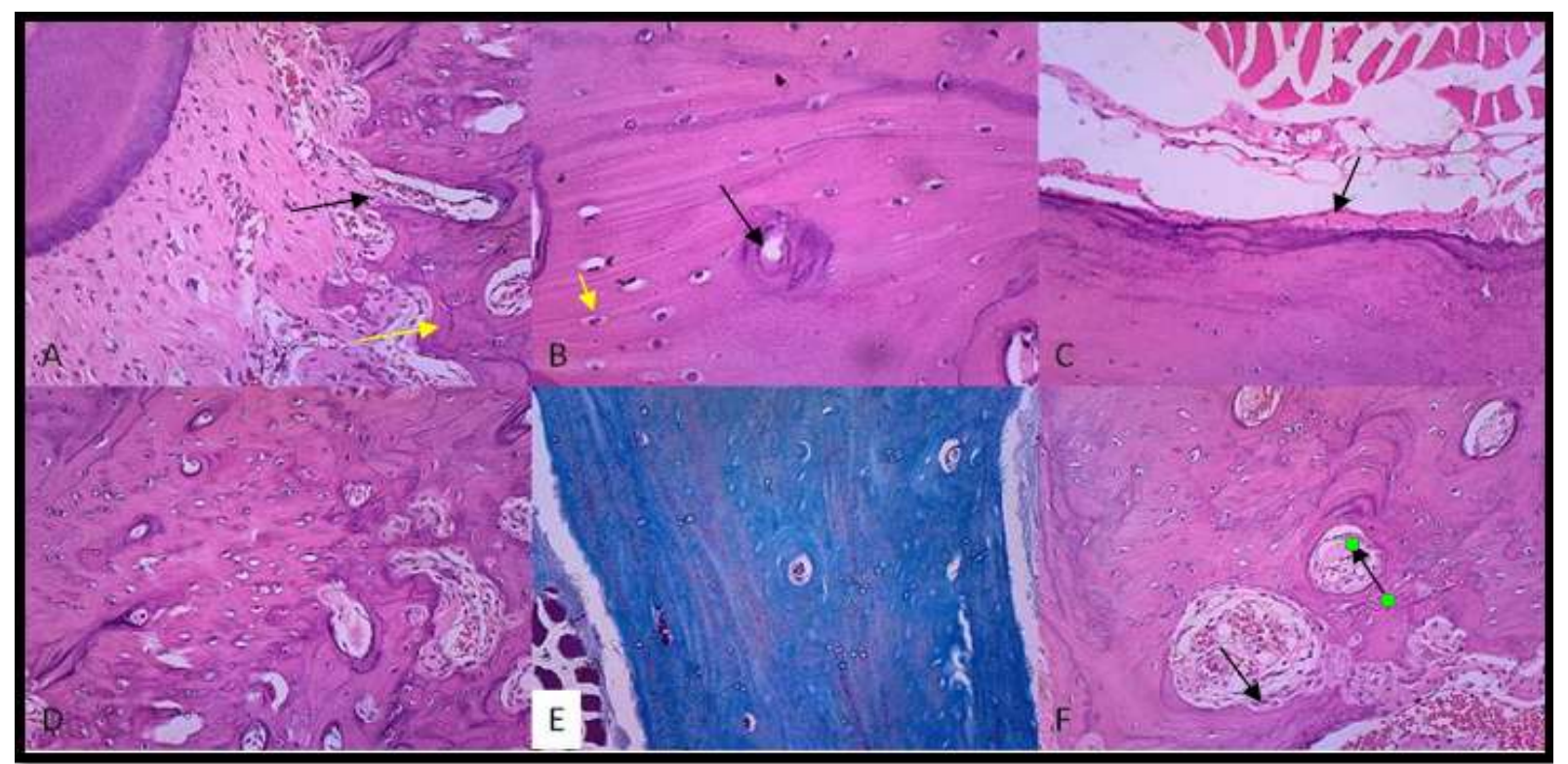

Fig.1:- Photomicrographs of control group 1 showing, A: Zucker kandle and Hershfield canals are of almost normal width (black arrow) with distinct layer of alveolar bone proper (yellow arrow). B: osteocytes are usually rounded with distinct lamina limitans (yellow arrow), haversian canals are rounded with almost regular caliber (black arrow). C: periosteum appeared with distinct fibrous layer (black arrow). D: spongy bone of regular lamellae. E: Masson trichrome stain showing blue dominating colour, F: endosteum with active osteoblast lining (black arrows). (Org.

Mag. x400)

\section{Group 2 (ovariectomy group):-}

The socket wall appeared irregular and scalloped with ill defined zones of alveolar bone proper. Zucker kandle and Hershfield canals were apparently widened with engorged blood vessels. Marked thinning of bone trabeculae (average thickness \pm 28.7 micrometer) with widening of marrow cavities. Osteoblasts appeared flattened with darkened nuclei while osteocytes showed shrunken dark nuclei with dilated lacunae or else empty lacunae were observed (average number of osteocytes was +10 ). Increase in the lymphocytic aggregation in the bone marrow together with fatty degeneration of some of its areas. Periosteum on the other hand showed a very thin detached layer of osteoblasts. In compact bone dilated Haversian canals were observed together with thick numerous reversal lines (Fig. $2 A, B, C, D, E \& F$ ).

Masson trichrome results:-Predominance of bright red areas is observed with increased degree of blue colour in spongy bone in comparison to compct bone. 


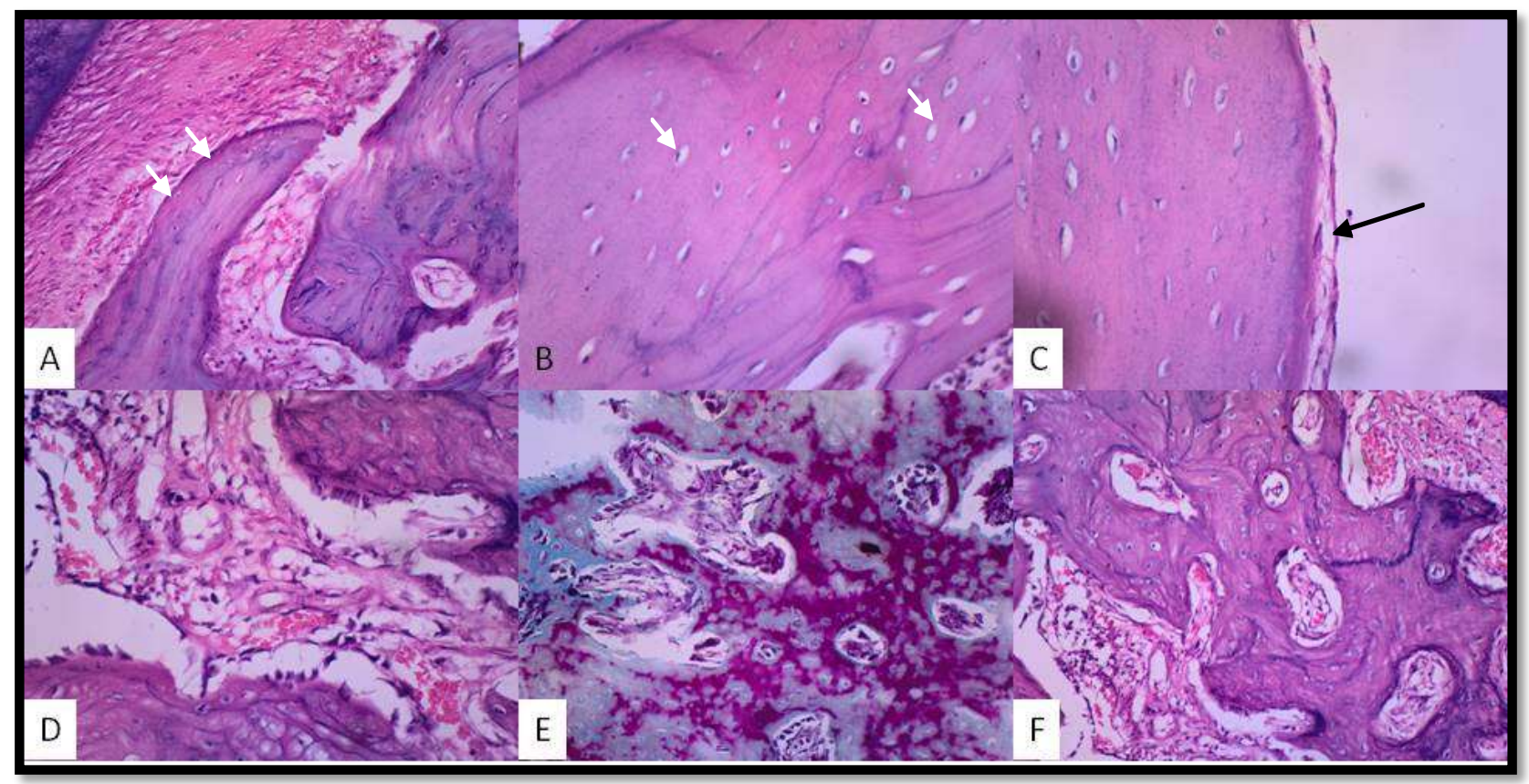

Fig.2. Photomicrographs of ovariectomy group 2 showing, A: widened Zucker kandle and Hershfield canals with no distinct layer of alveolar bone proper (white arrows). B: osteocytes lacunae are left empty or with shrunken cells

(white arrows). C: periosteum appeared with flattened non-active osteoblasts (black arrow) D: widened marrow cavities in spongy bone.E: Masson trichrome stain showing intermingling blue and red with dominating red colour, F: spongy bone of thinned lamellae. (Org. Mag. X400)

\section{Group 3 (ovx + alendronate group):-}

The socket wall appeared more regular and no scalloping was noticed still only limited zones of defined alveolar bone proper. Zucker kandle and Hershfield canals almost returned to normal width. Bone trabeculae are thicker (average thickness \pm 57.5 micrometer). Some osteoblasts appeared flattened with darkened nuclei others are active and cuboidal in shape while osteocytes showed clear lamina limitans in some zones or else empty lacunae were observed (average number of osteocytes was \pm 19 ). Increase in the lymphocytic aggregation in the bone marrow together with fatty degeneration persisted in some of its areas. Periosteum on the other hand showed a regular layer of active osteoblasts. In compact bone dilated haversian canals were observed together with numerous reversal lines (Fig. $3 A, B, C, D, E \& F$ ).

\section{Masson trichrome results:-}

Intermingling between red and blue areas was observed. 


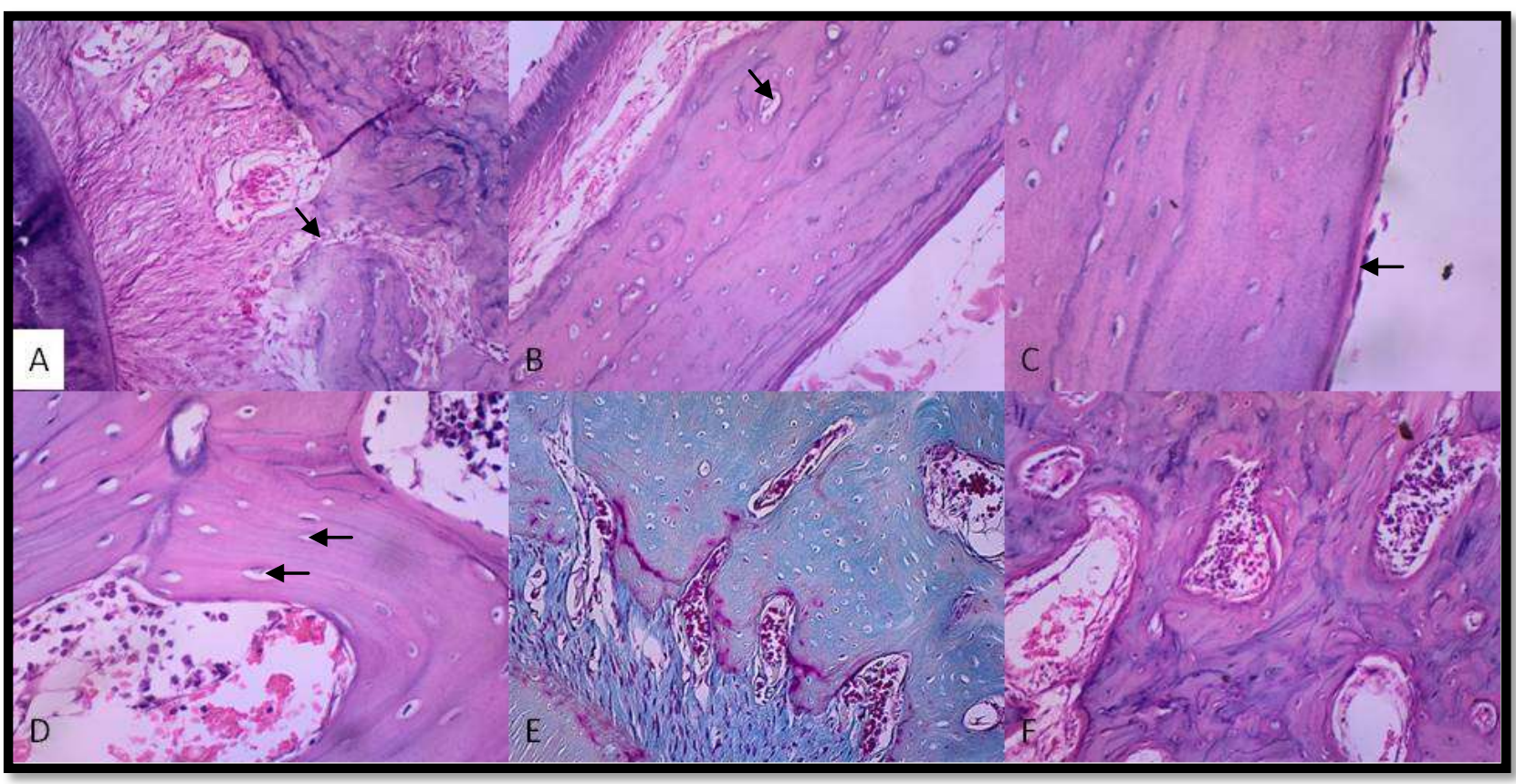

Fig. 3. Photomicrographs of ovx +Alendronate group (group 3) showing, A: almost normal Zucker kandle and Hershfield canals (black arrow) with well-defined layer of alveolar bone proper. B: dilated haversian canals in compact bone (black arrow). C: periosteum appeared with well defined osteoblasts (black arrow). D: osteocytes are rounded or as shrunken cells, widened marrow cavities in spongy bone (black arrows). E: Masson trichrome stain showing intermingling blue and red with dominating blue colour F: spongy bone of thickened lamellae. (Org. Mag. $\mathrm{X} 400)$

\section{Group 4 (ovx +stem cells group):-}

The socket wall appeared irregular and no scalloping was noticed still only limited zones of defined alveolar bone proper. Zucker kandle and Hershfield canals returned to normal width in some areas while they were widened in others. Increased thickness of bone trabeculae compared to group 2 (average thickness \pm 58.4 micrometer) esp. in interradicular region. Osteoblasts persisted as flattened in some areas while in active cuboidal form in others, while osteocytes showed clear lamina limitans in some areas and still shrunken in others or else few empty lacunae were observed (average number of osteocytes was \pm 21 ). Increase in the lymphocytic aggregation in the bone marrow together persisted with less degree of fatty degenration. Periosteum on the other hand appeared relatively thick with active osteoblasts and well defined osteoid. In compact bone, almost normal diameter of Haversian canal is regained with many reversal lines appeared ( Fig. $4 A, B, C, D, E \& F$ ).

\section{Masson trichrome results:-}

Intermingling between red and blue areas was observed, with predominance of blue colour especially in compact bone of anterior zone. 


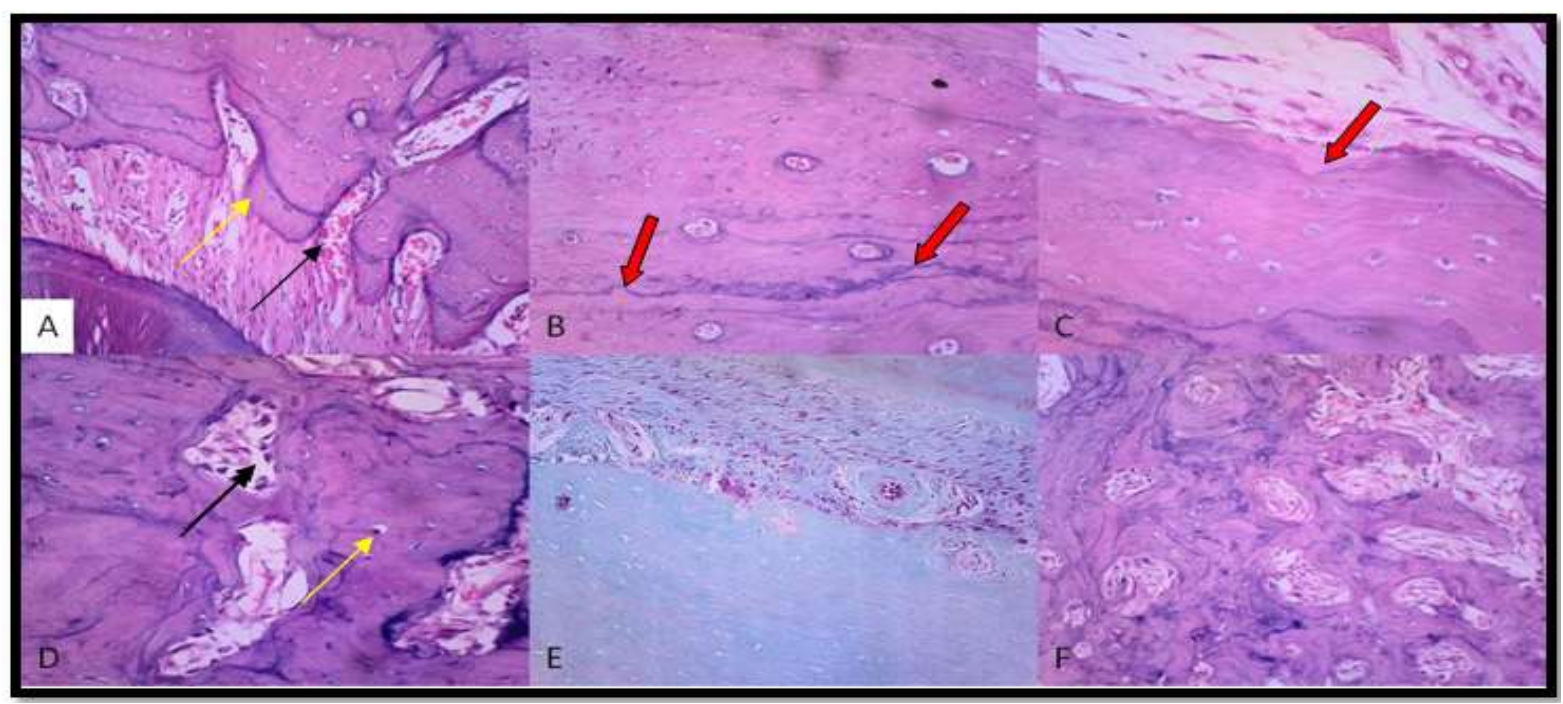

Fig.4. Photomicrographs of ovx +stem cells (group 4) showing, A: Zucker kandle and Hershfield canals are not wide (black arrow) with some areas of distinct alveolar bone proper (yellow arrow) B: regular haversian canals in compact bone with reversal lines (red arrows). C: periosteum appeared with cuboidal active osteoblasts with well defined osteoid layer (red arrow), D: osteocytes are rounded (yellow arrow), regular marrow cavities in spongy bone (black arrow) E: Masson trichrome stain showing dominating blue colour, F: spongy bone of thickened lamellae.

(Org. Mag. X400)

\section{Histomorphmetric analysis results:-}

In order to assess the degree of healing obtained by Alendronate or Stem cells histomorphometric analysis of the acquired photomicrographs was done to measure average thickness of bone trabeculae in spongy bone of posterior zone. (table 1, Fig. 5) data revealed significant decrease in trabecular width after ovariectomy however reversal effects were obtained both by using alendronate and stem cells with close values.

Table.1:-showing the average thickness of bone marrow trabeculae (in micrometers) in spongy bone of molar bearing area in each group.

\begin{tabular}{|l|c|}
\hline & THICKNESS in micrometer \\
\hline GP 1 & 60 \\
\hline GP2 & 28.7 \\
\hline GP3 & 57.5 \\
\hline GP4 & 58.5 \\
\hline
\end{tabular}




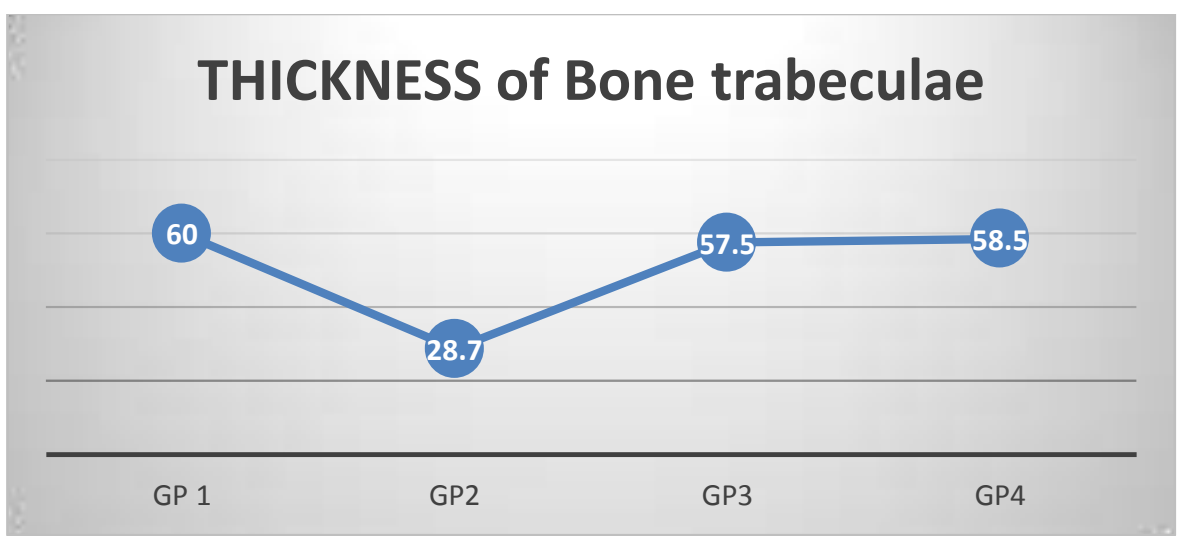

Fig.5:-Graph plot showing the average thickness of bone marrow trabeculae (in micrometers) in spongy bone of molar bearing area in each group.

On the other hand, Average number of osteocytes was counted in an area of $1 \mathrm{~mm}$ in diameter in spongy bone of posterior zone in each group (table 2, Fig. 6) Again data revealed significant decrease in osteocyte cell counts after ovarectomy while an augmentation occured both by using alendronate and stem cells with close values.

\begin{tabular}{|l|l|}
\hline & No Osteocytes \\
\hline GP 1 & 24 \\
\hline GP2 & 10 \\
\hline GP3 & 19 \\
\hline GP4 & 21 \\
\hline
\end{tabular}

Table.2:-showing the average thickness of bone marrow trabeculae (in micrometers) in spongy bone of molar bearing area in each group.

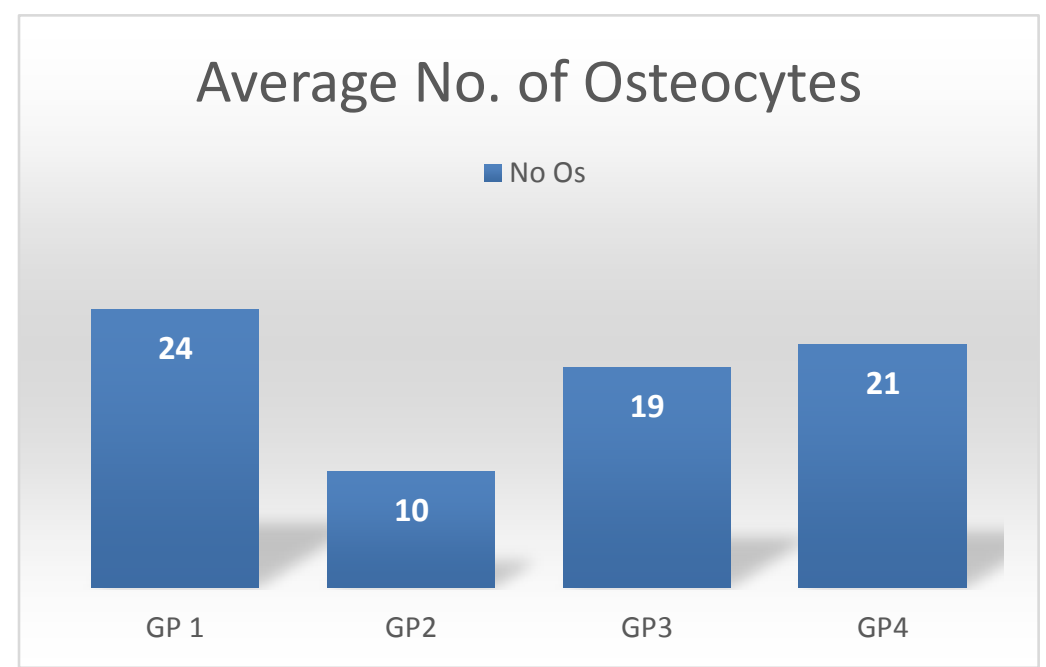

Fig.6:-graph plot showing the average numbers of osteocytes (in cells) per $1 \mathrm{~mm}^{2}$ in spongy bone of molar bearing area in each group.

There was no statistical significance between the mean collected data from groups 3 and 4 as compared together and in relation to the control group.

\section{Dissuasion:-}

One of the significant consequences of menopause recognized worldwide in women aged 65 and older (about 15 years after occurrence of menopause), is the physical and psychological disturbance caused by osteoporosis. Bone loss tends to be more pronounced in the years following menopause or bilateral ovariectomy. Loss of ovarian function itself is a risk for developing osteoporosis and the conservation of bone mass should be a concern. ${ }^{[36]}$ 
The classified organization of musculoskeletal stem cell compartment contained within the heterogeneous MSC pool has been documented. ${ }^{[37]}$ the multipotency of the BM-MSCs population as a whole has been well considered, showing that certain subsets of cells within the total population hold the ability to differentiate into skeletal phenotypes, including bone, muscle, fat, tendon, cartilage, and marrow stroma. ${ }^{[38]}$

The similarities in pathophysiologic response between human and rat skeleton have made the rat a valuable model in osteoporosis research. Adult female ovariectomized rats were used in this study to mimic the effect of physiologic hormonal imbalance in menopause. ${ }^{[39,40]}$

In ovariectomized rats group in our study, the socket wall showed ill-defined zones of alveolar bone proper. Zucker kandle and Hershfield canals were apparently wide with engorged blood vessels. Marked thinning of bone trabeculae with widening of marrow cavities was also observed. Osteocytes showed shrunken dark nuclei with dilated or else empty lacunae. In compact bone dilated Haversian canals were observed together with thick numerous reversal lines. These were the histological signs of osteoporosis in alveolar bone documented by Sadakazu Ejiri et al. ${ }^{[41]}$ That bone loss induced by ovariectomy (ovx) has been linked to oestrogen depletion and increased production of osteoclastogenic cytokines by bone marrow cells. Jau et al., showed that the T-cell co-stimulatory molecule CD40 ligand (CD40L) promote osteoblast proliferation and differentiation; regulate the SC production of the osteoclastogenic factors macrophage colony-stimulating factor, receptor activator of nuclear factor- $\kappa \mathrm{B}$ ligand, and osteoprotegerin; and up-regulate osteoclast formation .hence they concluded that cross-talk between T cells and SCs mediated by CD40L plays a pivotal role in the disregulation of osteoblastogenesis and osteoclastogenesis induced by ovx. ${ }^{[42]}$

Confirming to the previous, a decrease in the number of active osteoblasts were observed in the positive control group (group 1) of our research together with a decrease in the number and activity of osteocytes with evidence of shrunken nuclei to one side of the lacunae. Also there was an appearance of dilated and empty lacunae; this can be explained by osteocyte death by apoptosis as an effect of hormonal in balance. As the levels of receptor-interacting serine/threonine protein kinase 1 (RIP1) and RIP3 in osteocytes were proven to increased after ovariectomy, which suggest that necroptosis accelerates osteocyte loss under conditions of estrogen deficiency-induced osteoporosis in OVX rats. ${ }^{[43]}$

In Ovx group an increase in the lymphocytic aggregation in the bone marrow together with fatty degeneration of some of its areas were noticed. The literature reports that oestrogen depletion is related to an increase in food intake and weight in rodents. ${ }^{[4]}$ This increase in weight restricting from hyperphagia caused by ovariectomy and this caused an increase in fatty tissue mass generally. ${ }^{[45]}$ Another explanation could be attributed to the conclusion that with aging, osteoblasts are replaced by adipocytes within the bone marrow with significant consequences in osteoblast number, function, and survival. ${ }^{[46]}$

The apparently increased lymphocytic aggregation in the marrow cavities of the ovx rats could be linked to the inflammatory changes following vasculature disturbances occurred in menopausal osteoporosis. Bone and vasculature metabolism are so closely connected that, at a molecular level, arteries can interact with bone and vice versa. ${ }^{[47,48]}$ Following menopause, an arterial disorder is affecting bone; a bone, arteries or both tissues. For example, endothelial dysfunction itself has a potent downstream effect on bone metabolism by decreasing local production of nitric oxide and the inflammatory mediator prostaglandin $\mathrm{E}_{2}\left(\mathrm{PGE}_{2}\right)$ (both of which stimulate osteoblasts and inhibit osteoclasts) thus, decreasing production of $\mathrm{PGI}_{2}$ (which inhibits osteoclasts) and decreasing production of the bone matrix protein osteopontin. ${ }^{[49]}$ So, endothelial dysfunction could through local mediators, reduce osteoblastic and increase osteoclastic activity. ${ }^{[49]}$

In ovariectomized rats treated with alendronate, the socket wall appeared more regular with only limited zones of defined alveolar bone proper. Zucker kandle and Hershfield canals almost returned to normal appearance. Bone trabeculae appeared thicker. Some osteoblasts appeared flattened with darkened nuclei others were cuboidal in shape. Osteocytes showed clear lamina limitans in some zones or else empty lacunae were observed. Increase in the lymphocytic aggregation in the bone marrow together with fatty degeneration persisted in some areas. Periosteum on the other hand showed a regular layer of active osteoblasts. In compact bone less dilated haversian canals were observed together with numerous reversal lines. The effects of the bisphosphonate alendronate on the formation of bone and its resorption by osteoclasts were evaluated by Sugata et al., 2011 using a rabbit model. They proved that 
Alendronate administration suppressed the resorption and affected the mineral density and remodelling of bone tissue. ${ }^{[50]}$

This coincides with our results, where in group 3 that received alendronate treatment after ovariectomy, which was reinforced by the work of Xiong et al., who deduced that administration of alendronate to rats might inhibit alveolar bone resorption which might not lead to impairment of angiogenes associated with periapical diseases. [51] Alendronate is highly effective in preventing bone loss associated with the absence of endogenous oestrogen and inducing a continual increase in bone mass during treatment in animals. Similarly, ALN promotes the recovery of mineral density in humans due to its inhibitory action on osteoclasts. ${ }^{[52]}$

Duque and Rivas, 2007 proposed the hypothesis that this effect of Alendronate was performed via the differentiation of MSCs as anabolic effect which contradicted the common categorization of alendronate as an Antiresorptive agents like estrogens, selective estrogen-receptor modulators (SERMs), calcitonin, and bisphosphonates. where the mechanism of action of these compounds was thought to be restricted to the inhibition of osteoclastic activity and therefore of bone resorption. In general, bisphosphonates have been considered antiresorptive agents with limited effect on the osteoblasts. ${ }^{[53]}$ That was confirmed by our findings were trabeculae width thickened together with reduced dilatation of haversian canals and bone marrow cavities though a proportion of osteoblasts remained inactive even in the periosteum. Furthermore, such hypothesis was confirmed by the current Masson trichrome results of group 2 where patchy appearance of bright red and blue colour indicated limited increase in active bone formation though the blue colour was dominant.

Experimental group 4 in the current study treated by stem cells after ovariectomy exhibited active osteoblasts both in periosteum and lining marrow cavities. The socket wall appeared more regular and no scalloping was noticed, still only limited zones of defined alveolar bone proper. Zucker kandle and Hershfield canals returned to normal width in some areas while they were widened in others. Increased thickness of bone trabeculae esp. in inter radicular region. Osteoblasts persisted as flattened in some areas while in active cuboidal form in others, while osteocytes showed clear lamina limitans in some areas and still shrunken in others or else few empty lacunae were observed. Increase in the lymphocytic aggregation in the bone marrow together persisted with less degree of fatty degenration. In compact bone normal width of haversian canals is regained together with some reversal lines indicating new bone formation and remodelling.

This was confirmed by the Masson trichrome stain as new bone formation was demonstrated by the prevalence of blue colour .

These results come in accordance with Gao et al. and Takigami et al. who proved that injected MScs were shown preferentially engrafted into bone marrow and together with circulating osteoblast progenitor cells are capable of homing to the defect site and contribute to skeletal repair. ${ }^{[54,55]}$

On the contrary Zenhaeusern et Al., reported that MSCs did not prevent estrogen deficiency induced bone loss in rats after local or systemic administration of MSCs. ${ }^{[56]}$ Which was contradicted by Oshita et al., ${ }^{[57]}$ who deduced that MSCs contribute to a suppressive effect on osteoclastogensis by producing OPG which is known to be an inhibitory particle to RANKL-dependant osteoclastic differentiation.

Such contradictory findings may be attributed to the fact that transplantation of MSCs in vivo have failed to promote an osteogenic response in bone due to the inability of MSCs to home to the bone surface unless they were genetically modified. ${ }^{[58,59]}$ or after certain injuries. ${ }^{[60,61]}$ This has become a major obstacle for MSC transplantation. [54-61] Even if the transplanted MSCs make it to "bone," they are usually observed engrafting in the upper metaphysis, epiphysis, or within the sinusoids of bone marrow or the Haversian canals. The transplanted MSCs are removed from bone marrow within 4-8 weeks, and there is no evidence of long-term engraftment. ${ }^{[60-61-62]}$

The Appearance of fat tissue in osteoporotic group bone marrow and its gradual diminish in treated groups can be explained by the presence of a reciprocal relation between adipogenic and osteoblastic differentiation lineages that is governed by the expression of certain signaling molecules like PPAR $\gamma 2$ which is proven to convert stromal cells from an osteoblastic phenotype and reversibly expresses adipocyte features to terminally differentiated adipocytes. Moreover, PPAR $\gamma 2$ suppresses the expression of Cbfa1 and thereby osteoblast-specific genes. ${ }^{[63]}$

DISCLOSURE OF POTENTIAL CONFLICTS OF INTEREST 
The authors indicate no potential conflicts of interest.

\section{Reference:-}

1. Rosen CJ, Bilezikian JP. Anabolic therapy for osteoporosis. J Clin Endocrinol Metab 2001; 86:957-64.

2. Iwamoto J, Miyata A, Sato Y, Takeda T, Matsumoto H. Five-year alendronate treatment outcome in older postmenopausal Japanese women with osteoporosis or osteopenia and clinical risk factors for fractures. Ther Clin Risk Manag 2009; 5:773-9.

3. Lerner UH. Bone remodeling in post-menopausal osteoporosis. J Dent Res 2006; 85:584-95.

4. Kimmel DB. Mechanisms of action, pharmacokinetic and pharmacodynamic profile, and clinical applications of nitrogen containing biphosphonates. J Dent Res 2007; 86:1022-33.

5. Flanagan AM, Chambers TJ. Inhibition of bone resorption by bisphosphonates: interactions between bisphosphonats, osteoclasts, and bone. Calcif Tissue Int 1991; 49:407-15.

6. Hughes DE, Wright KR, Uy HL, Sasaki A, Yoneda T, Roodman GD, et al. Bisphosphonates promote apoptosis in murine osteoclasts in vitro and in vivo. J Bone Miner Res 1995; 10:1478-87.

7. Russel RGG, Rogers MJ. Bisphosphonates: from the laboratory to the clinic and back again. Bone 1999; 25:97106.

8. Zahrowski JJ. Bisphosphonate treatment: an orthodontic concern calling for a proactive approach. Am J Orthod Dentofacial Orthop 2007;131:311-20.

9. Rinchuse DJ, Rinchuse DJ, Sosovicka MF, Robison JM, Pendleton R. Orthodontic treatment of patients using bisphosphonates: a report of 2 cases. Am J Orthod Dentofacial Orthop 2007; 131:321-6.

10. Salazar M, Hernandes L, Ramos AL, Micheletti KR, Albino CC, Cuman RKN. Effect of teriparatide on induced teeth displacement in ovariectomized rats: a histomorphometric analysis. Am J Orthod Dentofacial Orthop 2011;139:e337-44

11. Choi J, Baek SH, Lee J, Chang Y. Effects of clodronate on early alveolar bone remodeling and root resorption related to orthodontic forces: a histomorphometric analysis. Am J Orthod Dentofacial Orthop 2010;138. 548.e1-548.e8.

12. Karras JC, Miller JR, Hodges JS, Beyer JP, Larson BE. Effect of alendronate on orthodontic tooth movement in rats. Am J Orthod Dentofacial Orthop 2009;136:843-7.

13. Wright NC, Looker AC, Saag KG et al. The recent prevalence of osteoporosis and low bone mass in the United States based on bone mineral density at the femoral neck or lumbar spine. J Bone Miner Res 2014;29:2520 2526.

14. Leslie WD, Lix LM, Finlayson GS et al. Direct healthcare costs for 5 years post fracture in Canada: A longterm population based assessment. Osteoporos Int 2013; 24:1697-1705.

15. Leslie WD, Morin SN. Osteoporosis epidemiology 2013: Implications for diagnosis, risk assessment, and treatment. Curr Opin Rheumatol 2014; 26:440-446.

16. Harvey N, Dennison E, Cooper C. The epidemiology of osteoporotic fractures. In: Rosen CJ, ed. Primer on the Metabolic Bone Diseases and Disorders of Mineral Metabolism. Ames, Iowa, USA: John Wiley \& Sons, 2013:348-356.

17. Papadimitropoulos EA, Coyte PC, Josse RG et al. Current and projected rates of hip fracture in Canada. CMAJ 1997;157:1357-1363.

18. Miller PD, Papapoulos SE, Kleerekoper M et al. Osteoporosis. In: Rosen CJ, ed. Primer on the Metabolic Bone Diseases and Disorders of Mineral Metabolism. 8th ed. Ames, Iowa, USA: John Wiley \& Sons, 2013:343-347.

19. Seriolo B, Paolino S, Casabella A et al. Osteoporosis in the elderly. Aging Clin Exp Res 2013;25(suppl 1):S2729.

20. Reid IR. Overview of pathogenesis. In: Rosen CJ, ed. Primer on the Metabolic Bone Diseases and Disorders of Mineral Metabolism. Ames, Iowa, USA: John Wiley \& Sons, 2013:357-360.

21. Baxter MA, Wynn RF, Jowitt SN et al. Study of telomere length reveals rapid aging of human marrow stromal cells following in vitro expansion. STEM CELLS 2004;22:675-682.

22. Nishida S, Endo N, Yamagiwa $\mathrm{H}$ et al. Number of osteoprogenitor cells in human bone marrow markedly decreases after skeletal maturation. J Bone Miner Metab 1999;17:171-177.

23. Muschler GF, Nitto H, Boehm CA et al. Age- and gender-related changes in the cellularity of human bone marrow and the prevalence of osteoblastic progenitors. J Orthop Res 2001;19:117-125.

24. Bellantuono I, Aldahmash A, Kassem M. Aging of marrow stromal (skeletal) stem cells and their contribution to age-related bone loss. Biochim Biophys Acta 2009;1792:364-370.

25. Chan CKF, Seo EY, Chen JY et al. Identification and specification of the mouse skeletal stem cell. Cell 2015;160:285-298. 
26. Worthley DL, Churchill M, Compton JT et al. Gremlin 1 identifies a skeletal stem cell with bone, cartilage, and reticular stromal potential. Cell 2015; 160:269-284.

27. Manolagas SC, Parfitt AM. What old means to bone. Trends Endocrinol Metab ,2010.21:369-374.

28. Khosla S, Riggs BL. Pathophysiology of age-related bone loss and osteoporosis. Endocrinol Metab Clin North Am 2005; 34:1015-1030, xi.

29. Stroup J, Kane MP, Abu-Baker AM. Teriparatide in the treatment of osteoporosis. Am J Health Syst Pharm 2008; 65:532-539.

30. Canalis E, Giustina A, Bilezikian JP. Mechanisms of anabolic therapies for osteoporosis.N Engl J Med 2007;357:905-916.

31. Shimomura Y., Shimizu H., Kobayashi I., Kobayashi S. Importance of feeding time in pairfed, ovariectomized rats. Physiology \& Behavior. 1989, 45(6):1197-1200.

32. Lasota A, Danowska-Klonowska D. Experimental osteoporosis- different methods of ovariectomy in female white rats. Annales Academiae Medicae Bialostocensis. 2004; 49: Suppl. 1.

33. Pytlik M., Kaczmarczyk-Sedlak I, oeliwiñski L., Janiec W., Rymkiewicz I. Effect of concurrent administration of Alendronate sodium and Retinol on development of changes in histomorphometric parameters of bones induced by ovariectomy in rats. Pol.J.Pharmacol.2004,56,571-579.

34. Kiernan J., Hu S., Grynpas MD., Davies JE., Stanford WL., Systemic Mesenchymal Stromal Cell Transplantation Prevents Functional Bone Loss in a Mouse Model of Age-Related Osteoporosis. Stem Cells Transl Med. 2016 May; 5(5):683-93.

35. Bancroft J.D. and Cook H.C.: Immunohistochemistry. In: Manual of histological techniques and diagnostic applications.1994, Churchill Livingstone, Edinburgh, London, Madrid, Melbourne, New York, Tokyo, pp. 236325.

36. Fernandes CE. Osteoporose. Rev Bras Med. 1998; 54:37-48.

37. Sarugaser R, Hanoun L, Keating A et al. Human mesenchymal stem cells self-renew and differentiate according to a deterministic hierarchy. PLoS One 2009;4:e6498.

38. Owen M, Friedenstein AJ. Stromal stem cells: Marrow-derived osteogenic precursors. Ciba Found Symp 1988;136:42-60. // \&//Pittenger MF, Mackay AM, Beck SC et al. Multilineage potential of adult human mesenchymal stem cells. Science 1999;284:143-147.

39. Omi N., Ezawa I.The effect of ovariectomy on bone metabolism in rats.Department of Food Nutrition, School of Home-Economics, Japan Women's University, Japa.Oct.1995 17(4): S163-S168.

40. Kennedy OD, Brennan O, Rackard SM, Staines A, O'Brien FJ, Taylor D, Lee TC. Effects of ovariectomy on bone turnover, porosity, and biomechanical properties in ovine compact bone 12 months postsurgery. J Orthop Res. 2009 Mar; 27(3):303-9.

41. Ejiri S, Toyooka E., Tanaka M.,Anwar RB., Kohno S. Histological and histomorphometrical changes in rat alveolar bone following antagonistic tooth extraction and/or ovariectomy. Archives of Oral Biology Volume 51, Issue 11, November 2006, Pages 941-950.

42. Jau-Yi Li,Hesham Tawfeek, Brahmchetna Bedi, Xiaoying Yang, Jonathan Adams, Kristy Y. Gao,Majd Zayzafoon, M. Neale Weitzmann, and Roberto Pacifici.Ovariectomy disregulates osteoblast and osteoclast formation through the T-cell receptor CD40 ligand. Proc Natl Acad Sci U S A. 2011 Jan 11; 108(2): 768-773.

43. Hongwang Cui, Yongjun Zhu and Dianming Jiang.The RIP1-RIP3 Complex Mediates Osteocyte Necroptosis after Ovariectomy in Rats. PLoS One. 2016; 11(3): e0150805.

44. Yoneda N, Saito S, Kimura M, Yamada M, Iida M, Murakani T, et al. The influence of ovariectomy on ob gene expression in rats. Horm Metab Res 1998;30:263-5.

45. Chen Y, Heiman ML. Increased weight gain after ovariectomy is not a consequence of leptin resistance. Am $\mathbf{J}$ Physiol Endocrinol Metab 2001;280:E315-22.

46. Ali AA, Weinstein RS, Stewart SA, Parfitt AM, Manolagas SC, Jilka RL 2005 Rosiglitazone causes bone loss in mice by suppressing osteoblast differentiation and bone formation. Endocrinology 146:1226-1235.

47. Demer LL and Tintut Y, Mechanisms linking osteoporosis with cardiovascular calcification. Curr Osteoporos Rep. 2009 Jul;7(2):42-6.

48. Hamerman D., Osteoporosis and atherosclerosis: biological linkages and the emergence of dual-purpose therapies. QJM. 2005 Jul; 98(7):467-84.

49. Bloomfield SA., Hogan HA., Delp MD. Decreases in bone blood flow and bone material properties in aging Fischer-344 rats. Clin Orthop Relat Res. 2002 Mar;(396):248-57.

50. Sugata Y., Sotome S., Yuasa M., Hirano M., Shinomiya K.,Okawa A.Effects of the systemic administration of alendronate on bone formation in a porous hydroxyapatite/collagen composite and resorption by osteoclasts in a bone defect model in rabbits. The bone and joint journal, Apr 2011. 
51. Xiong H1, Wei L, Hu Y, Zhang C, Peng B. Effect of alendronate on alveolar bone resorption and angiogenesis in rats with experimental periapical lesions. Int Endod J. 2010 Jun;43(6):485-91.

52. Rodan GA, Fleisch HA. Bisphosphonates: mechanisms of action (Perspectives). J Clin Invest 1996;97:2692-6.

53. Russell RG 2006 Bisphosphonates: From bench to bedside.Ann N Y Acad Sci 1068:367-401.

54. Gao J, Dennis JE, Muzic RF et al. The dynamic in vivo distribution of bone marrow-derived mesenchymal stem cells after infusion. Cells Tissues Organs 2001;169:12-20.

55. Takigami H, Kumagai K, Latson L, Togawa D, Bauer T, Powell K, Butler RS, Muschler GF. Bone formation following OP-1 implantation is improved by addition of autogenous bone marrow cells in a canine femur defect model. J Orthop Res. 2007 Oct;25(10):1333-42

56. Zenhaeusern G, Gubser P, Eisele P, Gasser O, Steinhuber A, Trampuz A, Handschin C, Luster AD, Hess C. A high-mobility, low-cost phenotype defines human effector-memory CD8+ T cells.B lood. 2009 Jan 1;113(1):959. doi: 10.1182/blood-2008-04-153262.

57. Oshita Koichi, Kunihiro Yamaoka, Nobuyuki Udagawa, Shunsuke Fukuyo, Koshiro Sonomoto, Keisuke Maeshima et al. Human Mesenchymal Stem Cells Inhibit Osteoclastogenesis Through Osteoprotegerin Production. American College of Rheumatology 2011; 63 1658-1667.

58. Gutwald R, Haberstroh J, Kuschnierz J et al. Mesenchymal stem cells and inorganic bovine bone mineral in sinus augmentation: Comparison with augmentation by autologous bone in adult sheep. Br J Oral Maxillofac Surg 2010;48:285-290.

59. Longobardi L, Granero-Molto F, O'Rear L et al. Subcellular localization of IRS-1 in IGF-I-mediated chondrogenic proliferation, differentiation and hypertrophy of bone marrow mesenchymal stem cells. Growth Factors 2009;27:309-320.

60. Chapel A, Bertho JM, Bensidhoum M et al. Mesenchymal stem cells home to injured tissues when co-infused with hematopoietic cells to treat a radiation-induced multi-organ failure syndrome. J Gene Med 2003;5:10281038.

61. Granero-Molto F, Weis JA, Miga MI et al. Regenerative effects of transplanted mesenchymal stem cells in fracture healing. Stem Cells 2009;27:1887-1898.

62. Meyerrose TE, De Ugarte DA, Hofling AA et al. In vivo distribution of human adipose-derived mesenchymal stem cells in novel xenotransplantation models. Stem Cells 2007;25:220-227.

63. Lecka-Czernik B, Gubrij I, Moerman E, Kajkenova O, Lipschitz D, Manolagas S,Jilka RL 1999 Inhibition of Osf2/Cbfa1 expression and terminal osteoblast differentiation by PPAR $\gamma 2$. J Cell Biochem 74:357-371. 